\title{
Breastfeeding in Infancy and Adult Cardiovascular Disease Risk Factors
}

\author{
Nisha I. Parikh, MD MPH, Shih-Jen Hwang, PhD, Erik Ingelsson, MD PhD, Emelia J. Benjamin, \\ MD ScM, Caroline S. Fox, MD MPH, Ramachandran S. Vasan, MD, and Joanne M. Murabito, \\ MD ScM \\ The National Heart, Lung, and Blood Institute's Framingham Heart Study (NIP, SJH, El, EJB, CSF, \\ RSV, JMM), Framingham, MA; Cardiovascular Division, Beth Israel Deaconess Medical Center, \\ Boston, MA (NIP); the National Heart, Lung, and Blood Institute, National Institutes of Health (SJH, \\ CSF), Bethesda, MD; Preventive Medicine and Cardiology Sections, Boston University School of \\ Medicine, Boston, MA(EJB, RSV); Epidemiology Section, Boston University School of Public Health, \\ Boston, MA (EJB); the Brigham and Women's Hospital, Harvard Medical School, Boston, MA (CSF); \\ the Section of General Internal Medicine, Boston University School of Medicine, Boston, MA (JMM)
}

\begin{abstract}
Background-Public health recommendations advocate breastfeeding in infancy as a means to reduce later-life obesity. Several prior studies relating breastfeeding to cardiovascular risk factors have been limited by lack of adjustment for maternal and participant confounding factors.

Methods-We ascertained breastfeeding history via questionnaire from mothers enrolled in the Framingham Offspring Study. In their young to middle-aged adult children enrolled in the Framingham Third Generation, we examined the relations between maternal breastfeeding history (yes, no) to cardiovascular risk factors, including: body mass index (BMI), HDL cholesterol, total cholesterol, triglycerides, fasting blood glucose, systolic and diastolic blood pressure. We applied Generalized estimating equations (GEE) to account for sibling correlations and adjusted for maternal and participant lifestyle, education and cardiovascular risk factors.
\end{abstract}

Results-In Third Generation participants ( $\mathrm{n}=962$, mean age $=41$ years, $54 \%$ women), $26 \%$ of their mothers reported breastfeeding. Compared to non-breastfed individuals, breastfed adult participants had lower multivariable-adjusted BMI $\left[26.1 \mathrm{~kg} / \mathrm{m}^{2}\right.$ vs. $\left.26.9 \mathrm{~kg} / \mathrm{m}^{2}, \mathrm{p}=0.04\right]$ and higher HDL

cholesterol levels [HDL $56.6 \mathrm{mg} / \mathrm{dL}$ vs. $53.7 \mathrm{mg} / \mathrm{dL}, \mathrm{p}=0.01$ ]. Upon additional adjustment for BMI the association between breastfeeding and HDL cholesterol was attenuated $(\mathrm{p}=0.09)$. Breastfeeding was not associated with total cholesterol, triglycerides, fasting blood glucose, systolic blood pressure or diastolic blood pressure.

Corresponding Author: Joanne M. Murabito, MD ScM, 73 Mount Wayte Ave, \#2, Framingham, MA 01702, Phone: 508-935-3461, Fax: 508-626-1262, Email: E-mail: murabito@bu.edu.

All authors had access to the data and a role in writing the manuscript.

Author Disclosures: None

Clinical Significance:

- Having been breastfed in infancy for greater than or equal to one month is associated with higher adult HDL levels and lower mean adult body mass index.

- Our study suggests that the benefits of breast feeding extend beyond childhood to adult health outcomes.

Publisher's Disclaimer: This is a PDF file of an unedited manuscript that has been accepted for publication. As a service to our customers we are providing this early version of the manuscript. The manuscript will undergo copyediting, typesetting, and review of the resulting proof before it is published in its final citable form. Please note that during the production process errors may be discovered which could affect the content, and all legal disclaimers that apply to the journal pertain. 
Conclusions-Breastfeeding in infancy is inversely associated with adult BMI and positively associated with HDL cholesterol. Associations between breastfeeding and BMI may mediate the association between breastfeeding and HDL cholesterol.

\section{Keywords}

Breastfeeding; lactation; risk factors; early nutrition; infancy; body mass index; HDL cholesterol

\section{Introduction}

Recent United States and World Health Organization recommendations strongly advocate breastfeeding in infancy as a means towards not only reducing infant infections, but also to protect against adverse adult health outcomes such as obesity.(1-3) Prior epidemiological evidence suggests that breastfeeding in infancy may also have protective effects on cardiovascular disease risk factor profiles $(4-9)$ and cardiovascular disease risk $(4 ; 10)$ in adulthood. Previous studies have demonstrated that breastfeeding in infancy may lead to small reductions in adolescent and adult blood pressure levels, $(4 ; 6 ; 11)$ decreased total cholesterol and LDL cholesterol levels in adulthood, $(4 ; 5 ; 8)$ and modest decreases in adult body mass index (BMI).(4)

Some prior studies have been limited by self-reported as opposed to directly measured maternal (12) and offspring cardiovascular disease risk factors.(12) Furthermore, some prior studies have been limited by failure to account for potential maternal and offspring confounders including socioeconomic status.(8) Highlighting the importance of accounting for socioeconomic status, a recent investigation in the Nurses Health Study did not demonstrate a significant association between breastfeeding and BMI upon adjustment for socioeconomic status.(12) Detailed risk factor ascertainment, sociodemographic data collection and maternal breastfeeding report among Framingham Heart Study Offspring mothers and their adult children in the Third Generation cohort allowed the opportunity to extend previous data on the association of breastfeeding in infancy with several cardiovascular disease risk factors in adulthood. We hypothesized that breastfeeding in infancy would be protective for cardiovascular disease risk factors but that these associations would be attenuated after accounting for maternal and participant socioeconomic and lifestyle characteristics.

\section{Materials and Methods}

\section{Study sample}

Participants for this study were part of the Third Generation cohort of the Framingham Heart Study; their mothers were members of the Offspring cohort. The Original Framingham Heart Study Cohort (13) and Framingham Offspring cohorts have been described elsewhere.(14)

Between July 1996 and May 1997, a breast health survey was mailed to Offspring cohort women that included questions regarding breastfeeding history of each of their children. The design and selection criteria for women chosen to receive the breast health survey has been previously described.(15) Briefly, women free of breast cancer with a first degree female relative enrolled in the Framingham Heart Study were sampled on the basis of one of three criteria: 1) women having a mother or sister with documented breast cancer; 2) women having a mother or sister with a non-gynecologic cancer; 3 ) women with mothers and/or sisters free of documented cancer. A total of 683 participants (77\%) returned the questionnaire (Figure).

Among these 683 offspring participants we excluded participants who completed the questionnaire who did not have a child $(\mathrm{n}=60)$, whose children didn't attend the third generation study $(\mathrm{n}=142)$ or who returned the questionnaire with incomplete or inconsistent information 
$(\mathrm{n}=88)$. Due to these exclusion criteria only $393(44 \%)$ of the offspring women survey sample were included in the analysis. These 393 mothers provided the source for the Third Generation Cohort participants $(n=962)$ (Figure). The 393 offspring women included in this study when compared to offspring women with children enrolled in the Third Generation cohort who are not included in this study $(\mathrm{n}=1114)$ had similar CVD risk factor profiles at enrollment into the Framingham Heart Study with the exception of a slightly higher diastolic blood pressure (77 vs. $75 \mathrm{mmHg}$ ) and lower rates of cigarette smoking (42 vs. 53\%) (p<0.05) (Appendix Table). The Boston University Medical Center Institutional Review Board approved the main study protocols for the Framingham Offspring and Third Generation cohort and all participants signed written informed consent.

\section{Risk factor collection}

In the current study, we used information on cardiovascular risk factors from the first and second offspring examinations (Offspring cohort mothers) and the first Third Generation examination (adult progeny) Details regarding the ascertainment of risk factors have been previously described.(16) Diabetes was defined as fasting plasma glucose $\geq 126 \mathrm{mg} / \mathrm{dL}$ or treatment with either insulin or oral hypoglycemic agents. Lipids were measured on twelvehour fasting venous blood samples collected in tubes containing 0.1\% EDTA. Plasma was separated by ultracentrifugation and plasma lipid concentrations (total cholesterol and highdensity lipoprotein cholesterol [HDL-C]) were measured as previously described.(17) Highdensity lipoprotein cholesterol was measured after precipitation of apo B-containing lipoproteins and low-density lipoprotein cholesterol concentrations were estimated using the Friedewald formula.(18) Intra-assay coefficients of variation for the Third Generation cohort cholesterol, triglycerides and high density lipoprotein were $0.5 \%, 1.1 \%$ and $1.4 \%$ respectively; Inter-assay coefficients of variation were $1.1,1.8$ and $3.0 \%$ respectively. Seated blood pressure was measured by a trained physician after the participant had rested for five minutes, and the average of two physician-obtained readings was used. Hypertension was defined as systolic blood pressure $\geq 140 \mathrm{~mm} \mathrm{Hg}$, or diastolic blood pressure $\geq 90 \mathrm{~mm} \mathrm{Hg}$ or use of blood-pressure lowering medications. Medication use was ascertained by physicians by detailed review of participant medication lists and Third Generation participants were asked to bring medication bottles to the clinic exam: including lipid lowering medications, oral contraceptive pills and hormone therapy use.

Participants were considered to be current smokers if they smoked at least one cigarette per day for the year prior to examination. Categories of body mass index (BMI) were defined according to National Heart Lung and Blood Institute and the World Health Organization guidelines(19;20) as follows: normal weight (BMI 18.5 to $25 \mathrm{~kg} / \mathrm{m} 2)$, overweight $(25 \leq \mathrm{BMI}<30$ $\left.\mathrm{kg} / \mathrm{m}^{2}\right)$, and obese $\left(\geq 30 \mathrm{~kg} / \mathrm{m}^{2}\right)$. Data regarding highest educational degree obtained was gathered via questionnaire and was categorized as follows: 1) High school diploma or equivalent or less; 2) Associates degree/junior college; 3) Bachelor's degree, and 4) Master's degree or doctorate. The physical activity index was reflective of physical activity performed in a typical 24-hour period using a structured questionnaire that asked participants to report the number of hours asleep; at rest; and in slight, moderate, and heavy activity in a typical day. $(21 ; 22)$ Moderate-to heavy alcohol intake was defined as consumption of more than 14 drinks per week in men or 7 drinks per week in women. Prevalent cardiovascular disease was defined as recognized myocardial infarction, coronary insufficiency (prolonged chest pain accompanied by reversible ischemic electrocardiographic changes), angina pectoris, stroke, transient ischemic attack, or intermittent claudication using previously described criteria.(23)

\section{Statistical Methods}

Descriptive statistics of Third Generation participant characteristics were grouped by maternal breastfeeding status (age- and sex-adjusted Generalized Estimated Equation [GEE] models 
were used to compare characteristics of participants by breastfeeding status). Descriptive statistics of maternal characteristics were presented according to whether mothers breastfed none, some, or all of their children. We examined cardiovascular risk factors described above as endpoints in the Third Generation Cohort. No cardiovascular events were examined in our study sample. GEE models were used to assess relations between dichotomous (ever versus never) breastfeeding status and the following Third Generation participant cardiovascular disease risk factors: BMI, total cholesterol, HDL cholesterol, triglycerides, fasting blood glucose, systolic blood pressure and diastolic blood pressure. The intra class correlations of BMI was 0.02 ( $\mathrm{p}=0.47$ ) among Third Generation Cohort siblings. We applied GEE models to account for related observations given the presence of siblings in the Third Generation cohort. Statistical models were constructed with adjustment for the following: Model 1: age, sex, hypertension treatment, lipid treatment, smoking status, birth order, oral contraceptive use, hormone replacement use, physical activity index and education level and Model 2: Model 1 covariates plus maternal smoking status, maternal education level, maternal BMI at study entry.

In secondary analyses, the dependent variable BMI was additionally adjusted for HDL cholesterol level and the outcome HDL cholesterol was additionally adjusted for the following covariates: participant BMI, participant alcohol intake and maternal HDL cholesterol. We also analyzed the dependent variables of cardiovascular disease risk factors dichotomously using clinically meaningful cut points. We tested potential effect modification by educational level. Finally, in order to assess the association of breastfeeding in infancy with an overall healthy lifestyle, we related breastfeeding status with participant higher education, smoking status and physical activity.

All statistical analyses were performed using SAS statistical software (version 8.1). A p-value of $<0.05$ was considered to be statistically significant.

\section{Results \\ Third Generation Participant characteristics}

Study sample characteristics grouped by breastfeeding status are shown in Table 1 . Twentysix percent of participants were reported by mothers to have been breastfed in infancy. Of those individuals that were breast-fed, the median breast feeding duration was 4 months (range 1 to 22 months), and $29.6 \%$ were breast-fed for more than 6 months. A higher prevalence of breastfed individuals had higher education levels and a lower prevalence of diabetes (Table 1).

\section{Maternal characteristics}

Characteristics of mothers by whether they breastfed none, all or some of their children are shown in Table 2. Mothers who breastfed all of their children also had the highest education levels, were the leanest and least likely to smoke.

\section{Breastfeeding status and cardiovascular disease risk factors in adulthood}

In model 1 that adjusted for participant cardiovascular disease risk factors, physical activity and education, breastfeeding (ever versus never) was associated with a lower BMI ( $\mathrm{p}=0.03$ ) (Table 3). Additionally adjusting for maternal factors in model 2 (maternal smoking, education and BMI) did not materially change the association between breastfeeding status and BMI ( $p=0.04$; adjusted mean BMI among those breastfed versus not was $26.1 \mathrm{~kg} / \mathrm{m}^{2} \mathrm{vs} .26 .9 \mathrm{~kg} /$ $\mathrm{m}^{2}$ respectively).

In model 1 adjusting for participant cardiovascular disease risk factors, physical activity and education, breastfeeding was associated with a higher HDL cholesterol level $(\mathrm{p}=0.01)$. Additionally adjusting for maternal factors (smoking, education and maternal BMI) did not 
materially change the association between breastfeeding status and HDL cholesterol level $(\mathrm{p}=0.01$; adjusted mean HDL cholesterol concentrations among those breastfed versus not were $56.6 \mathrm{mg} / \mathrm{dL}$ relative to $53.7 \mathrm{mg} / \mathrm{dL}$, respectively).

Breastfeeding (ever versus never) was not associated with participant total cholesterol, triglycerides, fasting blood glucose, systolic blood pressure or diastolic blood pressure in either model 1 or model 2 (Table 3 ).

\section{Secondary analyses}

\section{Association between breastfeeding status and BMI and HDL cholesterol} categories-Breastfeeding was inversely associated with low HDL cholesterol levels $(<40$ $\mathrm{mg} / \mathrm{dL}$ in men and $<50 \mathrm{mg} / \mathrm{dL}$ in women) even after accounting for participant and maternal cardiovascular disease risk factors, lifestyle and socioeconomic characteristics, multivariableadjusted [OR=0.63(0.42-0.96), $\mathrm{p}=0.03$ ] (Table 4). Breastfeeding was not significantly associated with any other dichotomized risk factors in fully adjusted models. (Table 4).

Additional model adjustments-Additionally adjusting multivariable model 2 for participant alcohol intake did not materially change the positive association between breastfeeding status and HDL cholesterol. Similarly, additionally adjusting model 2 for maternal HDL cholesterol did not materially change the positive association between breastfeeding status and HDL cholesterol.

Effect modification-There was no evidence of effect modification by educational level on the associations between breastfeeding with HDL or with BMI.

Association between breast feeding and healthy lifestyle-In fully adjusted models there were no significant associations between breastfeeding and having achieved a bachelor's degree or higher [OR=1.20(0.84-1.72)]; having a physical activity score of $\geq 37$ [1.20

(0.84-1.73)], or with current cigarette smoking [1.17(0.75-1.52)].

\section{Discussion}

\section{Summary of Findings}

In a community-based sample of 962 men and women in early to middle age, maternal report of breastfeeding was associated with modestly lower participant BMI and higher participant HDL cholesterol concentrations. Maternal report of breastfeeding was not significantly associated with offspring total cholesterol, triglycerides, fasting blood glucose, systolic or diastolic blood pressure. Breastfeeding was associated with higher mean HDL cholesterol concentrations even after accounting for participant and maternal education, lifestyle factors and cardiovascular disease risk factors. However, the association between maternal breastfeeding and participant HDL cholesterol appeared to be attenuated by adjustment for participant BMI.

\section{Breastfeeding and BMI}

In keeping with our data, prior studies have found an inverse association between breastfeeding in infancy and adolescent and adult adiposity. $(4 ; 7 ; 12 ; 24-27)$ Higher growth rates in early infancy among formula fed as compared to breastfed infants have been demonstrated in randomized trials of low birth weight and preterm infants(28) as well as in observational studies among normal birth weight babies.(29-31) In contrast to some prior reports, we did not find a significant attenuation in the association between breastfeeding and lower BMI upon adjustment for maternal and participant socioeconomic status defined using educational attainment. Furthermore, BMI is a moderately heritable trait,(32) yet adjustment for maternal 
BMI did not significantly diminish the associations. One prior study also demonstrated a significant inverse association between breastfeeding and childhood overweight even after adjusting for maternal obesity.(33) Our BMI data was directly ascertained in both mothers and study sample participants rather than self-reported.(12) Self-reported data used in prior studies could have led to some outcome misclassification with resultant biasing of measures towards the null value. Finally, our study was conducted in a sample unselected for sex and occupation, in contrast to prior investigations conducted among female registered nurses.(12)

Exact mechanisms by which breast milk confers protection against offspring weight gain are not known but aggregate data from several recent studies suggest that adipokines may potentially mediate the association. A recent laboratory study in rats has suggested that delayed weaning (meaning continuation of breast milk and delayed introduction of solid food) reduces plasma levels of the appetite-related peptide, ghrelin and also reduces gastric ghrelin cell development.(34) Ghrelin concentration increases during specific stages in rat infancy were formerly thought to be age as opposed to diet-related.(34) Furthermore, leptin concentrations in human breast milk have been demonstrated to inversely correlate with human infant weight gain up until 2 years of age.(35;36) In a separate randomized prospective study of feeding among preterm infants, serum leptin to fat mass ratio measured in adolescence was demonstrated to be lower in those randomized to donated banked breast milk as compared to formula feeding while in infancy.(37) Levels of other novel adipokines in human breast milk including epidermal and adipoctye fatty acid binding protein have been demonstrated to positively correlate with infant birth weight.(38)

\section{Breastfeeding and HDL cholesterol}

Whereas prior data suggests that breastfeeding is related to increases in total and LDLcholesterol levels in infancy and adulthood,(5) fewer studies have specifically examined the association between breastfeeding and later life HDL cholesterol levels. A recent study in a British birth cohort born in 1958 did not demonstrate an association between breastfeeding for $>1$ month and adult levels of HDL cholesterol.(27) A Dutch prospective study of adults aged 48-53 years, demonstrated a lower total to HDL cholesterol ratio among breastfed as compared to formula fed individuals.(8) In a randomized prospective study of feeding among preterm infants serum total to HDL cholesterol ratio measured in adolescence was lower among those previously randomized to banked donated breast milk as compared to formula feeding.(39)

\section{Choice of covariates for adjustment}

We felt it particularly important to adjust for education, body mass index and smoking status. Breastfeeding is more prevalent among women with a higher education which in turn is associated with a number of positive health indicators, including increased HDL cholesterol, (40)lower body mass index (41) and abstinence from smoking. Lower BMI and abstinence from smoking in turn are associated with higher HDL cholesterol levels.(42)

\section{Breastfeeding and other cardiovascular disease risk factors}

The absence of a significant association between breastfeeding in infancy and later life blood pressure in our sample is consistent with several prior investigations that did not find a significant association between breastfeeding and adult blood pressure. $(8 ; 43 ; 44)$ Furthermore, findings from a recent meta-analysis of several previously published studies, raise the concern that the inverse association between breast feeding and blood pressure from other studies may have been subject to selection or publication bias.(6)

We found no association between breastfeeding status and fasting blood glucose levels. This in keeping with prior studies in adolescents(45) as well as middle aged men(4) which both showed no association between breastfeeding in infancy and later life insulin resistance (as 
measured by homoeostasis model assessment or HOMA). We did not specifically study differences in rates of diabetes by breastfeeding status as the prevalence of diabetes was too low in our sample for meaningful analysis.

Given the lack of association between breastfeeding status and several cardiovascular disease risk factors studied, we assessed our statistical power to detect modest effects for associations between breastfeeding and the cardiovascular disease risk factors for which we did not detect significant associations. Taking sibling correlation into account, we had $80 \%$ power to detect a systolic blood pressure difference of $2.9 \mathrm{mmHg}$, a diastolic blood pressure difference of 2.0 $\mathrm{mmHg}$, total cholesterol difference of $7.0 \mathrm{mg} / \mathrm{dL}$, triglyceride difference of $17.2 \mathrm{mg} / \mathrm{dL}$, and fasting glucose difference of $2.9 \mathrm{mg} / \mathrm{dL}$. We had more modest power to detect smaller mean differences.

\section{Strengths and Limitations}

Direct and routine assessment of cardiovascular risk factors for two generations of participants, to account for both maternal covariates and offspring cardiovascular disease risk factors is a unique strength of our study. Additionally, risk factors were measured in offspring in adulthood while most prior reports examined the relation of breastfeeding to childhood risk factors. Several limitations should be acknowledged as well. Breastfeeding assessment was done decades after birth of participants which could have led to recall bias. However, the recall of whether or not a women breastfed her child has been shown to be accurate for $\geq 20$ years later. (46) Furthermore our study relied on maternal as compared to self-reported breastfeeding history, which has been demonstrated to be more accurate.(47) We did not adjust for other components of infant diet nor did we account for birth weight in our multivariable analysis. It has been demonstrated that low birth weight infants tend to breastfeed for shorter durations and also tend to have rapid catch up growth which is associated with later life obesity.(48) We also did not account for paternal factors as not all Third Generation participants have fathers in the Framingham Offspring cohort. Our study participants are of white European ancestry therefore these findings may not be generalizable to other ethnic populations. We accounted for socioeconomic status by means of highest education degree obtained which may not have fully accounted for socioeconomic differences.(49) HDL subfractions, which have demonstrated accuracy in predicting cardiovascular disease,(50) were not measured in this study. Although the incubation period between exposure and outcome in our study is relatively long, it is being increasingly recognized that early life exposures affect adult health. In turn, evidence suggests that cholesterol and BMI measured in middle age, confer later higher lifetime CVD risk.(51)

Potential selection bias from the breast health survey sampling scheme cannot be excluded; however, Offspring mothers with adult children enrolled in the Third Generation cohort not included in our study did not differ with respect to BMI and HDL cholesterol levels from the Offspring mothers included in the study. Since the alternatives to breastfeeding in the 1960s and 1970s differed from what is available today, these comparisons may not be relevant to current long-term breastfeeding effects. We do not assess the exclusivity of breastfeeding within our study framework. Nor were we able to carry out an analysis of risk factor levels among siblings discordant for breastfeeding as we had few of these in our study sample to permit a meaningful analysis. A discordant sibling pair analysis may have permitted better control of unmeasured potentially confounding maternal and family level factors. We did not account for the dietary intake of participants (ie. fat, carbohydrate and protein intake). We may have limited power to detect very modest differences in blood pressure, total cholesterol, triglycerides and fasting glucose. We did not account for multiple testing in our interpretation of results. Using the most conservative approach, given that Model 1 and Model 2 adjustments were highly correlated, and there were 7 separate dependent variables, the Bonferroni 
correction would have yielded an $\alpha$ level for significance of $0.05 / 7=0.007$. Finally, this is an observational study and therefore we cannot infer causality.

\section{Implications and directions for future study}

Our findings confirm previous reports of a protective association between breastfeeding and later life adiposity (as measured by BMI). Although the net reductions in BMI demonstrated in our study are modest, the beneficial effect at the population level may have important public health relevance. The risk of cardiovascular disease death and congestive heart failure have been demonstrated to increase even with small incremental increases in BMI,(52;53) suggesting that even modest differences in excess adiposity may increase cardiovascular disease mortality risks. Furthermore, the mechanisms underlying the association between lower adulthood BMI among individuals breastfed in infancy, are arguably of considerable importance. Our findings taken in conjunction with recent experimental evidence linking adipokines to breastmilk and infant weight suggest that further elucidating mechanisms relating early life nutrition and later life cardiometabolic risk factor profile is an important area of research. Furthermore, informed decisions about whether or not to breastfeed affect more than 4 million women annually(54) who give birth in the United States. Thus, understanding the association of breastfeeding with cardiovascular disease risk factors in later life remains an important public health issue.

\section{Conclusions}

Breastfeeding in infancy was associated with a modestly reduced BMI and elevated HDL cholesterol levels in adulthood after accounting for several participant and maternal characteristics. The association between breastfeeding and HDL cholesterol was attenuated upon accounting for participant BMI. Studies elucidating the mechanisms underlying early life nutrition and later life adiposity are warranted.

\section{Acknowledgments}

Dr. Murabito had full access to all of the data in the study and takes responsibility for the integrity of the data and the accuracy of the data analysis

Funding Source: Supported by a National Institute of Health / National Heart, Lung, and Blood Institute, contract N01-HC-25195, 2K24 HL 04334 (RSV)

\section{Appendix Table}

Cardiovascular disease risk factors among Offspring women with breastfeeding information ( $\mathrm{n}=393$ ) versus Offspring women not in our sample but with children enrolled in Third generation $(n=1114)$, means for continuous variables and percentages where denoted

\begin{tabular}{|l|c|c|c|}
\hline & $\begin{array}{c}\text { Offspring women not sampled } \\
\mathbf{n = 1 1 4}\end{array}$ & $\begin{array}{c}\text { Offspring women sampled } \\
\mathbf{n = 3 9 3}\end{array}$ & P-value \\
\hline Age, years & 37 & 36 & 0.21 \\
\hline Body Mass Index, $\mathrm{kg} / \mathrm{m} 2$ & 24.9 & 24.4 & 0.45 \\
\hline SBP, $\mathrm{mmHg}$ & 117 & 118 & 0.23 \\
\hline DBP, $\mathrm{mmHg}$ & 75 & 77 & $<.001$ \\
\hline Total cholesterol, $\mathrm{mg} / \mathrm{dL}$ & 193 & 192 & 0.80 \\
\hline HDL-cholesterol, $\mathrm{mg} / \mathrm{dL}$ & 57 & 57 & 0.67 \\
\hline
\end{tabular}




\begin{tabular}{|c|c|c|r|}
\hline & $\begin{array}{c}\text { Offspring women not sampled } \\
\mathbf{n = 1 1 1 4}\end{array}$ & $\begin{array}{c}\text { Offspring women sampled } \\
\mathbf{n}=\mathbf{3 9 3}\end{array}$ & P-value \\
\hline Current Smoking & $53 \%$ & $42 \%$ & 0.001 \\
\hline
\end{tabular}

\section{Reference List}

1. Gartner LM, Morton J, Lawrence RA, et al. Breastfeeding and the use of human milk. Pediatrics 2005 February;115(2):496-506. [PubMed: 15687461]

2. Office of Women's Health. US Department of Health and Human Services; 2006. Available from: URL: http://www.womenshealth.gov/breastfeeding/index.cfm?page=Campaign

3. Primary care interventions to promote breastfeeding: U.S. Preventive Services Task Force recommendation statement. Ann Intern Med 2008 October 21;149(8):560-4. [PubMed: 18936503]

4. Martin RM, Ben Shlomo Y, Gunnell D, et al. Breast feeding and cardiovascular disease risk factors, incidence, and mortality: the Caerphilly study. J Epidemiol Community Health 2005 February;59(2): 121-9. [PubMed: 15650143]

5. Owen CG, Whincup PH, Odoki K, et al. Infant feeding and blood cholesterol: a study in adolescents and a systematic review. Pediatrics 2002 September;110(3):597-608. [PubMed: 12205266]

6. Owen CG, Whincup PH, Gilg JA, Cook DG. Effect of breast feeding in infancy on blood pressure in later life: systematic review and meta-analysis. BMJ 2003 November 22;327(7425):1189-95.

[PubMed: 14630752]

7. Owen CG, Martin RM, Whincup PH, et al. The effect of breastfeeding on mean body mass index throughout life: a quantitative review of published and unpublished observational evidence. Am J Clin Nutr 2005 December;82(6):1298-307. [PubMed: 16332664]

8. Ravelli AC, van der Meulen JH, Osmond C, et al. Infant feeding and adult glucose tolerance, lipid profile, blood pressure, and obesity. Arch Dis Child 2000 March;82(3):248-52. [PubMed: 10685933]

9. Rudnicka AR, Owen CG, Strachan DP. The effect of breastfeeding on cardiorespiratory risk factors in adult life. Pediatrics 2007 May;119(5):e1107-e1115. [PubMed: 17473082]

10. Rich-Edwards JW, Stampfer MJ, Manson JE, et al. Breastfeeding during infancy and the risk of cardiovascular disease in adulthood. Epidemiology 2004 September;15(5):550-6. [PubMed: 15308954]

11. Martin RM, Ness AR, Gunnell D, et al. Does breast-feeding in infancy lower blood pressure in childhood? The Avon Longitudinal Study of Parents and Children (ALSPAC). Circulation 2004 March 16;109(10):1259-66. [PubMed: 14993142]

12. Michels KB, Willett WC, Graubard BI, et al. A longitudinal study of infant feeding and obesity throughout life course. Int J Obes (Lond). 2007 April 24;

13. Dawber TR, Kannel WB. An approach to longitudinal studies in a community: the Framingham Study. Ann N Y Acad Sci 1963 May 22;107:539-56. [PubMed: 14025561]

14. Feinleib M, Kannel WB, Garrison RJ, et al. The Framingham Offspring Study. Design and preliminary data. Prev Med 1975 December;4(4):518-25. [PubMed: 1208363]

15. Murabito JM, Evans JC, Larson MG, et al. Family breast cancer history and mammography: Framingham Offspring Study. Am J Epidemiol 2001 November 15;154(10):916-23. [PubMed: 11700246]

16. Kannel WB, Feinleib M, McNamara PM, et al. An investigation of coronary heart disease in families. The Framingham offspring study. Am J Epidemiol 1979 September;110(3):281-90. [PubMed: 474565]

17. McNamara JR, Schaefer EJ. Automated enzymatic standardized lipid analyses for plasma and lipoprotein fractions. Clin Chim Acta 1987 June 30;166(1):1-8. [PubMed: 3608193]

18. Friedewald WT, Levy RI, Fredrickson DS. Estimation of the concentration of low-density lipoprotein cholesterol in plasma, without use of the preparative ultracentrifuge. Clin Chem 1972 June;18(6): 499-502. [PubMed: 4337382]

19. Obes Res. Vol. 6. National Institutes of Health; 1998 Sep. Clinical Guidelines on the Identification, Evaluation, and Treatment of Overweight and Obesity in Adults--The Evidence Report; p. 51S-209S. 
20. WHO Technical Report Series. Vol. 894. Geneva, Switzerland: World Health Organization; 2000. WHO Consultation on Obesity. Obesity: Preventing and Managing the Global Epidemic.

21. Kannel WB, Sorlie P. Some health benefits of physical activity. The Framingham Study. Arch Intern Med 1979 August;139(8):857-61. [PubMed: 464698]

22. Sherman SE, D'Agostino RB, Cobb JL, Kannel WB. Physical activity and mortality in women in the Framingham Heart Study. Am Heart J 1994 November;128(5):879-84. [PubMed: 7942478]

23. Cupples, LA.; D'Agostino, RB, Sr. Some risk factors related to the annual incidence of cardiovascular disease and death using pooled repeated biennial measurements: Framingham Study, 30-year followup. In: Kannel, WB.; Wolf, PA.; Garrison, RJ., editors. The Framingham Heart Study: an Epidemiologic Investigation of Cardiovascular Disease. Washington, DC: NIH Publication; 1987. p. 87-203.

24. Arenz S, Ruckerl R, Koletzko B, von Kries R. Breast-feeding and childhood obesity--a systematic review. Int J Obes Relat Metab Disord 2004 October;28(10):1247-56. [PubMed: 15314625]

25. Gillman MW, Rifas-Shiman SL, Berkey CS, et al. Breast-feeding and overweight in adolescence. Epidemiology 2006 January;17(1):112-4. [PubMed: 16357604]

26. Victora, CG.; Barros, F.; Lima, RC., et al. BMJ. Vol. 327. 2003 Oct 18. Anthropometry and body composition of 18 year old men according to duration of breast feeding: birth cohort study from Brazil; p. 901

27. Rudnicka AR, Owen CG, Strachan DP. The effect of breastfeeding on cardiorespiratory risk factors in adult life. Pediatrics 2007 May;119(5):e1107-e1115. [PubMed: 17473082]

28. McGuire W, Anthony MY. Formula milk versus term human milk for feeding preterm or low birth weight infants. Cochrane Database Syst Rev. 2001;(4)CD002971

29. Butte NF, Wong WW, Hopkinson JM, et al. Infant feeding mode affects early growth and body composition. Pediatrics 2000 December;106(6):1355-66. [PubMed: 11099589]

30. Dewey KG, Heinig MJ, Nommsen LA, et al. Growth of breast-fed and formula-fed infants from 0 to 18 months: the DARLING Study. Pediatrics 1992 June;89(6 Pt 1):1035-41. [PubMed: 1594343]

31. Michaelsen KF, Larsen PS, Thomsen BL, Samuelson G. The Copenhagen Cohort Study on Infant Nutrition and Growth: breast-milk intake, human milk macronutrient content, and influencing factors. Am J Clin Nutr 1994 March;59(3):600-11. [PubMed: 8116536]

32. Coady SA, Jaquish CE, Fabsitz RR, et al. Genetic variability of adult body mass index: a longitudinal assessment in framingham families. Obes Res 2002 July;10(7):675-81. [PubMed: 12105290]

33. Mayer-Davis EJ, Rifas-Shiman SL, Zhou L, et al. Breast-feeding and risk for childhood obesity: does maternal diabetes or obesity status matter? Diabetes Care 2006 October;29(10):2231-7. [PubMed: 17003298]

34. Fak F, Friis-Hansen L, Westrom B, Wierup N. Gastric ghrelin cell development is hampered and plasma ghrelin is reduced by delayed weaning in rats. J Endocrinol 2007 February;192(2):345-52. [PubMed: 17283234]

35. Miralles O, Sanchez J, Palou A, Pico C. A physiological role of breast milk leptin in body weight control in developing infants. Obesity (Silver Spring) 2006 August;14(8):1371-7. [PubMed: 16988079]

36. Dundar NO, Anal O, Dundar B, et al. Longitudinal investigation of the relationship between breast milk leptin levels and growth in breast-fed infants. J Pediatr Endocrinol Metab 2005 February;18(2): 181-7. [PubMed: 15751607]

37. Singhal A, Farooqi IS, O'Rahilly S, et al. Early nutrition and leptin concentrations in later life. Am J Clin Nutr 2002 June;75(6):993-9. [PubMed: 12036804]

38. Bronsky J, Karpisek M, Bronska E, et al. Adiponectin, adipocyte fatty acid binding protein, and epidermal fatty acid binding protein: proteins newly identified in human breast milk. Clin Chem 2006 September;52(9):1763-70. [PubMed: 16873294]

39. Singhal A, Cole TJ, Fewtrell M, Lucas A. Breastmilk feeding and lipoprotein profile in adolescents born preterm: follow-up of a prospective randomised study. Lancet 2004 May 15;363(9421):15718. [PubMed: 15145629]

40. Demakakos P, Nazroo J, Breeze E, Marmot M. Socioeconomic status and health: the role of subjective social status. Soc Sci Med 2008 July;67(2):330-40. [PubMed: 18440111] 
41. Maty SC, Lynch JW, Raghunathan TE, Kaplan GA. Childhood socioeconomic position, gender, adult body mass index, and incidence of type 2 diabetes mellitus over 34 years in the Alameda County Study. Am J Public Health 2008 August;98(8):1486-94. [PubMed: 18556612]

42. Linn S, Fulwood R, Carroll M, et al. Serum total cholesterol: HDL cholesterol ratios in US white and black adults by selected demographic and socioeconomic variables (HANES II). Am J Public Health 1991 August;81(8):1038-43. [PubMed: 1853996]

43. Kolacek S, Kapetanovic T, Luzar V. Early determinants of cardiovascular risk factors in adults. B. Blood pressure. Acta Paediatr 1993 April;82(4):377-82. [PubMed: 8318806]

44. Leeson CP, Kattenhorn M, Deanfield JE, Lucas A. Duration of breast feeding and arterial distensibility in early adult life: population based study. BMJ 2001 March 17;322(7287):643-7. [PubMed: 11250848]

45. Lawlor DA, Riddoch CJ, Page AS, et al. Infant feeding and components of the metabolic syndrome: findings from the European Youth Heart Study. Arch Dis Child 2005 June;90(6):582-8. [PubMed: 15908621]

46. Kark JD, Troya G, Friedlander Y, et al. Validity of maternal reporting of breast feeding history and the association with blood lipids in 17 year olds in Jerusalem. J Epidemiol Community Health 1984 September;38(3):218-25. [PubMed: 6470599]

47. Troy LM, Michels KB, Hunter DJ, et al. Self-reported birthweight and history of having been breastfed among younger women: an assessment of validity. Int J Epidemiol 1996 February;25(1):122-7. [PubMed: 8666479]

48. Lande B, Andersen LF, Henriksen T, et al. Relations between high ponderal index at birth, feeding practices and body mass index in infancy. Eur J Clin Nutr 2005 November;59(11):1241-9. [PubMed: 16106264]

49. Braveman PA, Cubbin C, Egerter S, et al. Socioeconomic status in health research: one size does not fit all. JAMA 2005 December 14;294(22):2879-88. [PubMed: 16352796]

50. Buring JE, O'Connor GT, Goldhaber SZ, et al. Decreased HDL2 and HDL3 cholesterol, Apo A-I and Apo A-II, and increased risk of myocardial infarction. Circulation 1992 January;85(1):22-9. [PubMed: 1728453]

51. Lloyd-Jones DM, Leip EP, Larson MG, et al. Prediction of lifetime risk for cardiovascular disease by risk factor burden at 50 years of age. Circulation 2006 February 14;113(6):791-8. [PubMed: 16461820]

52. Calle EE, Thun MJ, Petrelli JM, et al. Body-mass index and mortality in a prospective cohort of U.S. adults. N Engl J Med 1999 October 7;341(15):1097-105. [PubMed: 10511607]

53. Kenchaiah S, Evans JC, Levy D, et al. Obesity and the risk of heart failure. N Engl J Med 2002 August 1;347(5):305-13. [PubMed: 12151467]

54. Martin JA, Hamilton BE, Sutton PD, et al. Births: final data for 2004. Natl Vital Stat Rep 2006 September 29;55(1):1-101. 


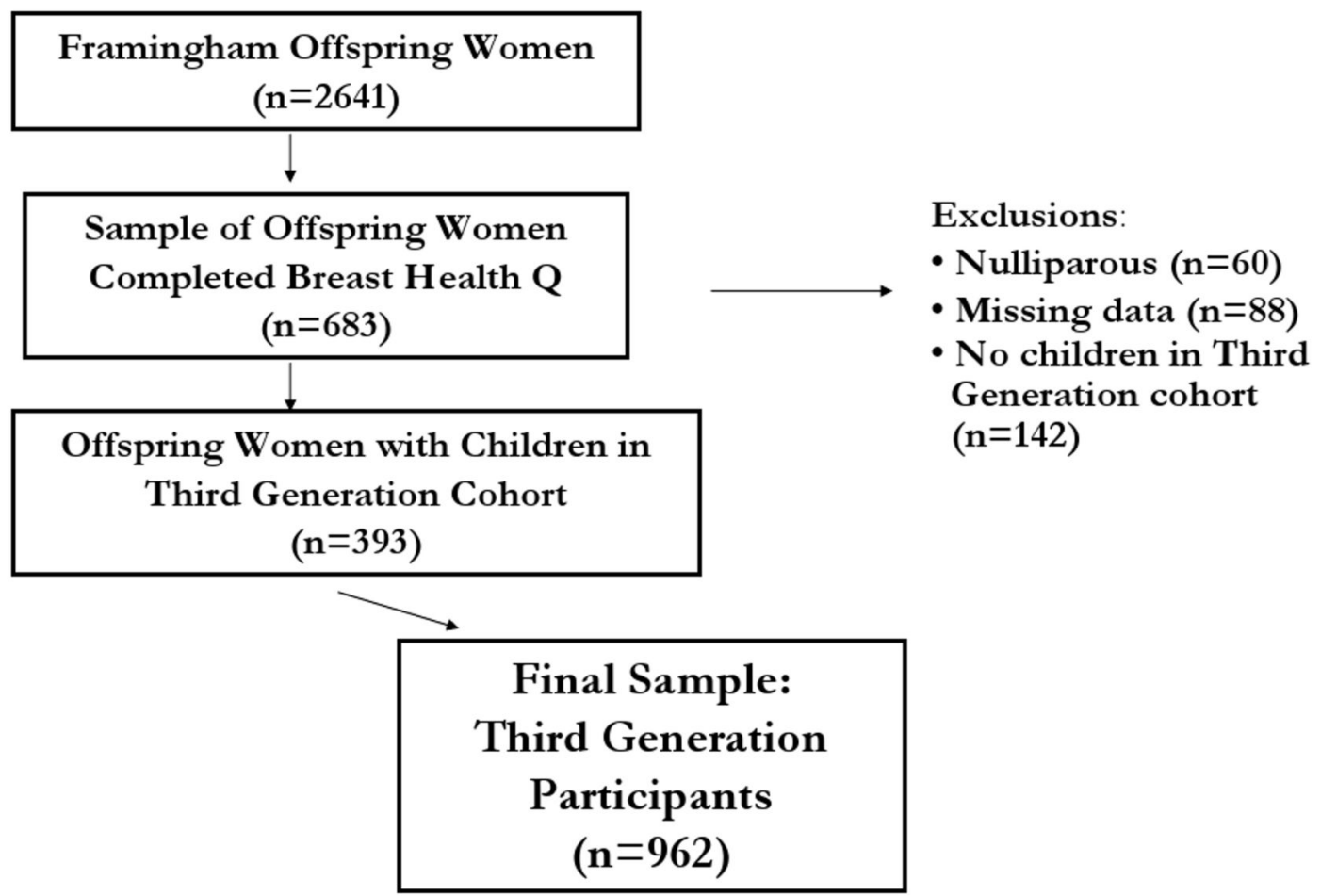

Figure. Creation of Study Sample based on Framingham Offspring (Maternal) Breastfeeding Information 
Table 1

Third Generation Participant Characteristics by Breastfeeding Status

\begin{tabular}{|c|c|c|}
\hline Characteristics & \multicolumn{2}{|c|}{$\begin{array}{c}\text { Third Generation Participant } \\
\text { Breastfeeding Status }\end{array}$} \\
\hline Means (SD) or (\%) & $\begin{array}{c}\text { No } \\
n=712\end{array}$ & $\begin{array}{c}\text { Yes } \\
\mathbf{n}=\mathbf{2 5 0}\end{array}$ \\
\hline Age (years) & $41 \pm 7$ & $41 \pm 9$ \\
\hline Women $(\%)$ & 54.8 & 50.0 \\
\hline Birth order (among siblings) & $2.4+1.4$ & $2.0 \pm 1.2$ \\
\hline Systolic Blood Pressure (mm Hg) & $117 \pm 15$ & $118 \pm 15$ \\
\hline Diastolic Blood Pressure (mm Hg) & $76 \pm 10$ & $75 \pm 10$ \\
\hline Fasting Blood Glucose (mg/dL) & $95 \pm 19.5$ & $94 \pm 10$ \\
\hline Total cholesterol (mg/dL) & $190 \pm 34$ & $190 \pm 32.5$ \\
\hline HDL cholesterol $(\mathrm{mg} / \mathrm{dL})^{*}$ & $54 \pm 16$ & $56 \pm 15$ \\
\hline Triglycerides (mg/dL) & $116 \pm 90.5$ & $108 \pm 79$ \\
\hline Body Mass Index $\left(\mathrm{kg} / \mathrm{m}^{2}\right)$ & $26.9 \pm 5.4$ & $26.3 \pm 5.0$ \\
\hline Waist Circumference (cm) & $93 \pm 15$ & $93 \pm 14$ \\
\hline Physical Activity Index & $37.6 \pm 8$ & $37.6 \pm 8$ \\
\hline Hypertension, $\%$ & 7.8 & 8.0 \\
\hline Lipid treatment, $\%$ & 5.9 & 7.2 \\
\hline Diabetes Mellitus, $\%$ & 3.0 & 1.2 \\
\hline Obesity $(\mathrm{BMI}>=30), \%$ & 23.5 & 20.4 \\
\hline Overweight ( $25=<$ BMI $<30), \%$ & 35.8 & 32.0 \\
\hline Total cholesterol $>200, \%$ & 36.5 & 36.3 \\
\hline Triglyceride $>150, \%$ & 21.4 & 16.0 \\
\hline
\end{tabular}


Characteristics

Third Generation Participant Breastfeeding Status

Means (SD) or $(\%) \quad \begin{gathered}\text { No } \\ \mathbf{n}=712 \quad \text { Yes }\end{gathered}$

$\mathrm{n}=712$
Smoking, \%

Moderate Alcohol Intake ${ }^{\dagger}, \%$

Education Level ${ }^{*}$

- High School or less, \%

- Some college \%

- Bachelors, \%

- Masters or higher, \%

* Age- and sex-adjusted $\mathrm{p}<0.05$

${ }^{+}$

Defined as $>7$ drinks per week in women and $>14$ drinks per week in men
2.7

20.4

3.8

17.0

15.3

15.4

18.2

\section{8}

14.8

3.2

9.6

30.9

32.3

41.0

18.5 
Parikh et al.

Table 2

Selected Maternal Characteristics at Study Entry by Breastfeeding Status*

\begin{tabular}{|c|c|c|c|}
\hline \multirow{2}{*}{$\begin{array}{l}\text { Characteristic } \\
\text { Means (SD) or N (\%) }\end{array}$} & \multicolumn{3}{|c|}{$\begin{array}{c}\text { Maternal Breast Feeding Report } \\
\text { Breastfed }\end{array}$} \\
\hline & $\begin{array}{l}\text { No children } \\
\quad \mathbf{n}=\mathbf{2 5 0}\end{array}$ & $\begin{array}{l}\text { Some children (not } \\
\text { all) } \\
\mathbf{n}=63\end{array}$ & $\begin{array}{l}\text { All children } \\
\mathbf{n}=\mathbf{8 0}\end{array}$ \\
\hline Age at study entry & $35.8 \pm 7.6$ & $35.3 \pm 9.0$ & $40.1 \pm 7.6$ \\
\hline Parity (number live births) & $3.3 \pm 1.6$ & $2.8 \pm 1.4$ & $3.7 \pm 1.5$ \\
\hline Systolic Blood Pressure (mm Hg) & $117.6 \pm 14.2$ & $116.7 \pm 14.6$ & $121.1 \pm 18.6$ \\
\hline Diastolic Blood Pressure (mm Hg) & $77.2 \pm 9.1$ & $76.4 \pm 10.8$ & $78.9 \pm 10.3$ \\
\hline Total cholesterol (mg/dL) & $192.9 \pm 36.9$ & $187.3 \pm 33.8$ & $196.6 \pm 40.8$ \\
\hline LDL cholesterol (mg/dL) & $119.4 \pm 33.4$ & $114.0 \pm 35.1$ & $123.0 \pm 36.9$ \\
\hline HDL cholesterol (mg/dL) & $56.9 \pm 14.3$ & $58.2 \pm 13.0$ & $56.9 \pm 17.3$ \\
\hline Triglycerides (mg/dL) & $82.0 \pm 57.9$ & $69.9 \pm 40.0$ & $84.0 \pm 52.4$ \\
\hline Body Mass Index $\left(\mathrm{kg} / \mathrm{m}^{2}\right)$ & $24.2 \pm 4.5$ & $23.8 \pm 3.6$ & $24.5 \pm 4.6$ \\
\hline Hypertension, $\mathrm{n}(\%)$ & $27(10.8)$ & $12(19.1)$ & 12(19.1) \\
\hline Diabetes Mellitus, $\mathrm{n}(\%)$ & $1(0.4)$ & 0 & 0 \\
\hline Smoking, $\mathrm{n}(\%)$ & $100(40)$ & $24(38.1)$ & $24(30)$ \\
\hline Overweight, $\mathrm{n}(\%)$ & $41(16)$ & $11(17)$ & $16(20)$ \\
\hline Obesity, $(\mathrm{n} \%)$ & $35(14)$ & $8(12)$ & $7(9)$ \\
\hline \multicolumn{4}{|l|}{ Education Level $^{* *}$} \\
\hline - Less than High School n(\%) & $13(5.7)$ & $11(18.3)$ & $6(9.1)$ \\
\hline - Some college $n(\%)$ & $155(68.0)$ & $34(56.7)$ & $28(42.4)$ \\
\hline - Bachelors n(\%) & $55(24.12)$ & $12(20)$ & $21(31.8)$ \\
\hline - Masters or higher $\mathrm{n}(\%)$ & $5(2.2)$ & $3(5)$ & $11(16.7)$ \\
\hline
\end{tabular}

* Risk factors taken at first exam the woman achieved age 20 years or older (5 mothers were younger than 20 at examination cycle 1 therefore, examination cycle 2 data was used)

** data available in 60 women who breastfed some children, 228 who did not breastfeed and 66 women who breastfed all of their children. 


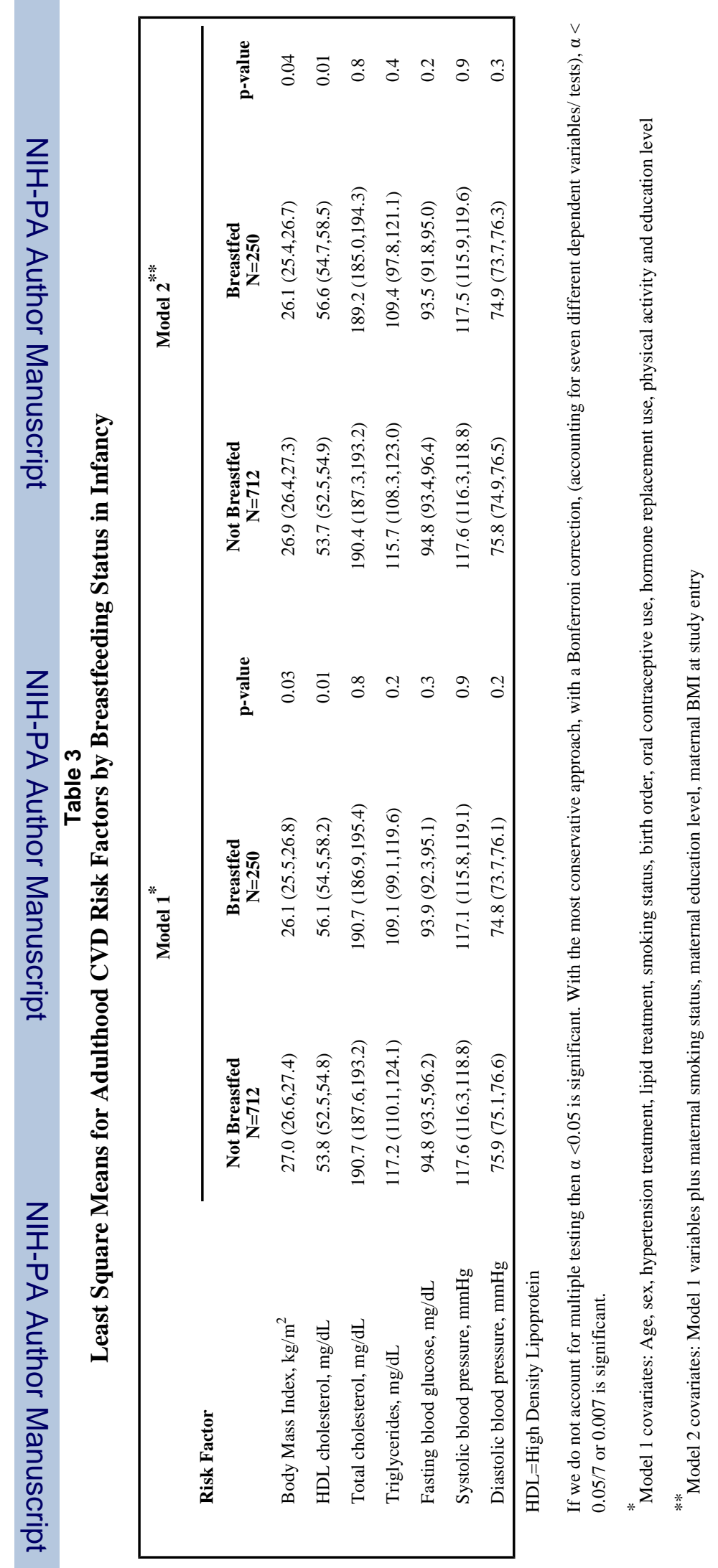

Am J Med. Author manuscript; available in PMC 2010 July 1. 


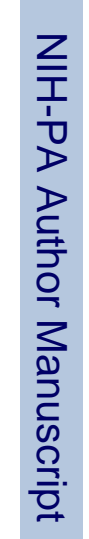

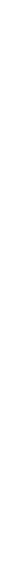

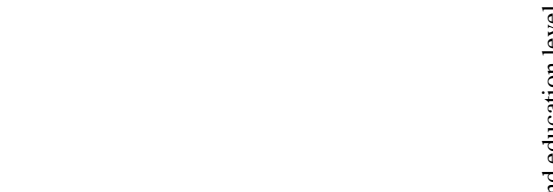

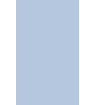

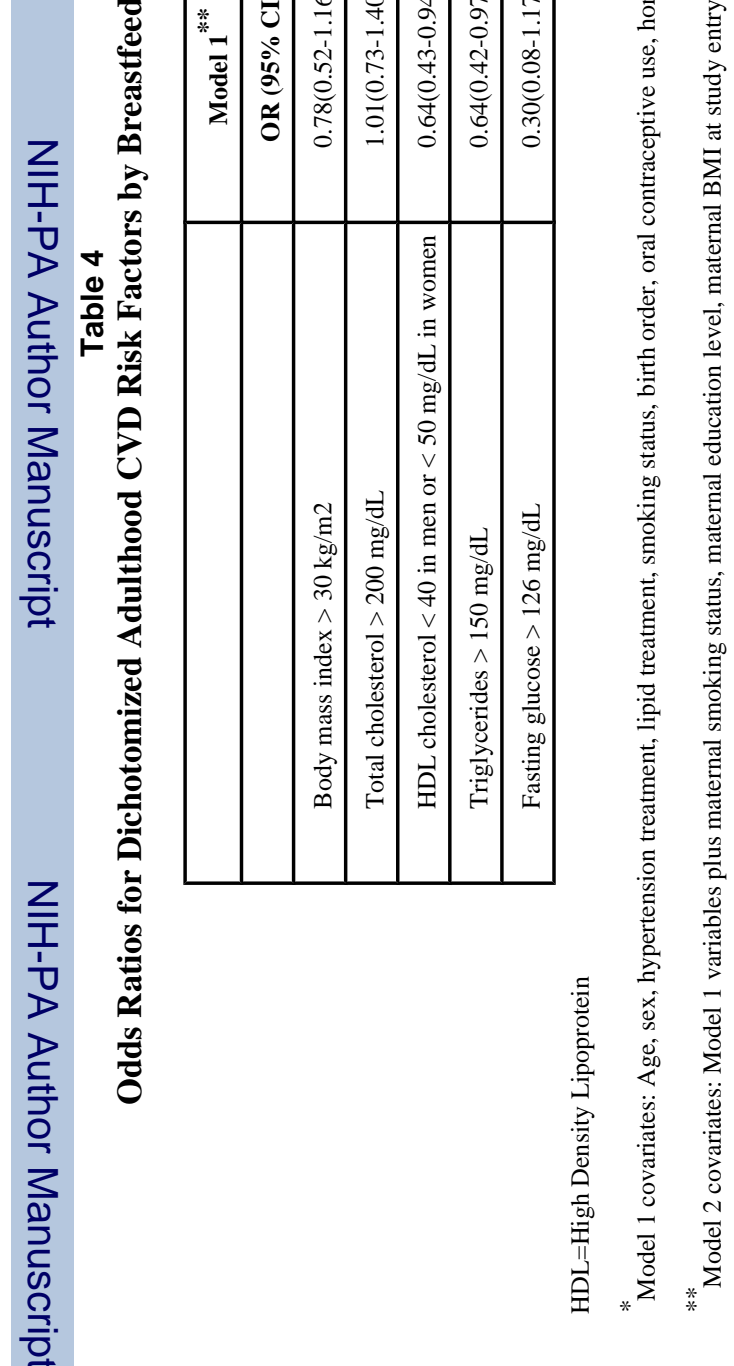

Am J Med. Author manuscript; available in PMC 2010 July 1. 